\title{
Development of a Teaching Model in Virtual Learning Environment to Enhance Computational Competencies in the $21^{\text {st }}$ Century
}

\author{
https://doi.org/10.3991/ijim.v15i13.21791 \\ Noppadol Rungrangtanapol, Jintavee Khlaisang $(\bowtie)$ \\ Chulalongkorn University, Bangkok, Thailand \\ jintavee.mechula.ac.th
}

\begin{abstract}
In the 21st century, computing and other necessary skills have become imperative for today's learners. Memorizing a book or one-way communication is incapable of fully developing all the skills required. Along with changes in the new curriculum structure in the computational science courses which are aimed to improve computational thinking skills. In Thailand, students do not have enough experience in calculation methods. Teachers must therefore provide instruction in a format that promotes computational thinking and the skills necessary for the 21 st century. The sample was 400 students from public and private schools in the same amount to develop the model, which was calculated based on the population of high school students throughout Bangkok, Thailand. It was found that the current learning model was unable to develop computational thinking concepts and 21 st century skills. Therefore, the researchers have the concept of developing a teaching model that focuses on problem-solving along with the use of a design thinking approach in a virtual learning environment. To enable students with no experience with computational thinking skills to develop computational thinking skills to a competent standard. The objective is to also develop other skills, which are essential skills in the 21 st century at the same time.
\end{abstract}

Keywords - Computational Science, Computational Competencies, Virtual Learning Environment, 21 st century

\section{Introduction}

The 4th industrial age has evolved to use Artificial Intelligence (AI) systems to replace human labor [1]. Today's students must be prepared to solve these challenges [2]. This situation affects the social occupational structure and the management of teaching and they need to be addressed in a new career development structure [3]. Developing the potential of future personnel beyond to excel in a society with artificial intelligence. There has been an emergence of new occupations and challenges at a time with the unemployment rate is rising [1]. There is intense competition in the labor market throughout the world, especially for local, national, and international employees. However, it has been discovered that one of the best ways of producing prospective workers 
is through improved education [4]. Education has the potential to make a great contribution to the skills and knowledge needed for future industrial evolution.

In Thailand, the focus is on developing students to think computationally. To be based on digital technology and media and information literacy, which is not limited to thinking like a computer, but also analytical thought processes to solve problems which occur in real life [5]. This concept is a concept in computational science, which is a subject that forms the basis of systematic thinking, imagination, creativity, and abstract thinking is designed to develop and improve children's thinking processes [6].

The Institute for the Promotion of Teaching Science and Technology, Thailand has focused on developing learners to have the knowledge and the skill required, that are comparable to the standard of international student learning science and links that knowledge with the process of self-development. There are hands-on activities to allow learners to follow scientific processes and use 21 st century skills. In the 2018 academic year, the schools had to use the science curriculum (a revised version from 2017) and utilize skills and knowledge from different subjects, occupations, whilst using modern technology to enhance the learning of science. Technological knowledge and skills, design, and computational science are fundamental in the 21 st century and these skills are well connected with science.

At the same time, the learning environment of the new generation of children is full of big databases, media, and modern information technology. In particular, new media is emerging every day in a form of digital technology, but there are still many students do not have access to technological devices. Therefore, teaching management in educational institutes must consider the consistency of students' characteristics and environment. The purpose of this course is to enhance learners' skills and quality of life for the 21 st century. The establishment and development of a new generation is to build immunity for the new generation. Including the development of learners to be able to adapt and face the changes in the future. the research on the field of mobile learning and refugee education could act as a proposal to upgrade the quality of education not only for other vulnerable social group, based on their specific characteristics, but also of all students in general [7].

Developing students with computational conceptual skills is essential are requires timely techniques and styles to develop them. It is imperative to enable student to develop their own ideas to think step-by-step as well as being able to create innovative works to meet the actual needs. They should be able to design guidelines to be appropriate, cost-effective and efficient. The purpose of this study is to develop a learning model that management in education institutes can use to enhance their programs. This model will be adaptable so management can adjust the basest on the background of the school and the needs of the students. The researchers therefore began to survey the population of high school students across Bangkok by collecting equal amounts of data from public and private schools to develop them in a way that best suited the needs of the learners.

This paper collected data from a sample of past teaching models and summarizes the teaching models that are appropriate for the characteristics of today's learners. That also includes a management model for teaching computational Science in a virtual learning environment so that students can develop both computational competencies and 
essential skills for the $21^{\text {st }}$ century through various activities. The concept its important, and approach to development are presented in the details below.

\section{$2 \quad$ Literature Review}

\subsection{Computational science}

Education today focuses on developing the skills of the learners to live with quality in the 21st century [8]. Information and communication computational science courses focus on helping students develop the abilities to analyze and solve problems in a stepby-step systematic manner that has morality, ethics, and values in the creative use of science and technology [9]. And now computational science courses are courses that focus on teaching children to be able to think computationally and has a foundation in digital technology and another foundation in media and information literacy, which is not limited to thinking like a computer. Rather, it is an analytical thinking process to be used to solve problems that occur in real life [10]. The scope of teaching and learning of computational science can be divided into 3 sub-categories of knowledge as follows: 1. Computational thinking or computational concepts. 2.Fundamentals of digital technology 3 . Fundamentals of media and information literacy.

\subsection{Computational thinking}

Computational concepts are the problem-solving skills that begin with understanding complex problems in a holistic manner. Firstly, determine the area of the problem "What is the problem?" and "What is not a problem?". and digest the problems in each related section, designing, solving problems, and defining algorithms. For all the problems to be solved student need to think of the computational concepts using both using the computer and combining that with other techniques that don't require a computer [11]. There are fundamental skills in the study of computational science. The most important skills for the 21 st century workforce are the set of skills involved in creating and interpreting algorithms such as, problem analysis, digesting big problems step-bystep and making it manageable and digestible [12].

\subsection{Virtual learning environment}

The virtual environment is organized or used in virtual classroom to simulate the situation for students and teachers in the structure. And the instructor is inside the developed structure and encourages mutual interaction Instructional design is designed according to the learning objectives to evolve into a virtual classroom model based on blended learning [13]. Interactive teaching in this way is used to enable the teaching to achieve its learning objectives effectively in terms of performance and learning needs of different learners and a wide range of users [8]. 


\section{$2.4 \quad 21$ st century skills}

21 st century skills are the core skills known as the 4C 1. Critical Thinking and Problem solving 2. Communication 3. Collaboration 4. Creativity and Innovation [2]; [13] In the 21 st century, thinking and learning skills will develop through innovative techniques and resources [14]; [11]. Researchers have chosen to develop a teaching model in virtual learning environment to develop both computational competencies and $21 \mathrm{st}$ century skills.

From a related Literature Review researchers plans to develop a teaching model in virtual learning environment to enhance computational competencies in the 21 st century in line with the theoretical frameworks of computational science and a virtual learning environment was shown in Fig.1

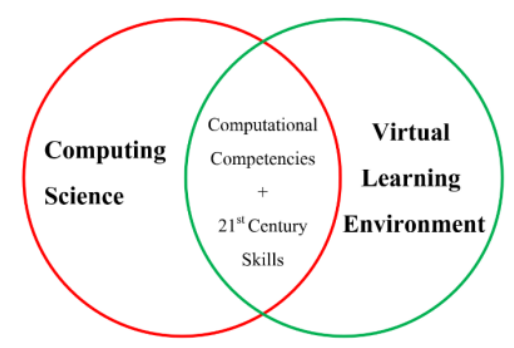

Fig. 1. Framework of a Teaching Model in Virtual Learning Environment to Enhance Computational Competencies in the 21 st Century

By studying additional papers, the researchers have synthesized the components of the conceptual framework as follows.

The computational science components are a fundamental necessity in planning design content for the learners, including identifying indicators of the learner's potential from the activities, including.

1. Elements of developing calculated thinking skills and systematic thinking

2. Decision-making skills developing components

3. Elements of joint learning skills development

4. Problem Solving Skills Development

The virtual learning environment elements are elements that create interaction between learners and teachers, allowing them to have experiences of collaborating with others including experiences from different simulations that cannot be done in the real world. Components of the virtual learning environment consist of.

1. Simulation or context of the learner

2. Structure or network

3. Communication and Interaction

4. Coordinate the time dimension and do not synchronize the time dimension.

5. Analytical thinking and problem solving of learners 


\subsection{Learner differences}

Computational concept skills components and $21^{\text {st }}$ century skills are essential structures to form the learner's systematic thinking characteristics. And solving problems systematically, includes.

1. Problem solving skills

2. Pattern recognition skills

3. Abstract thinking skills

4. Algorithm designs

5. Collaborative skills

\section{Survey for Research}

\subsection{Computational science}

From the elements of the conceptual framework to the development of a teaching model in virtual learning environments to enhance computational competencies in the $21^{\text {st }}$ century, the researchers designed each element with the students in mind throughout. The objective is to collect data, analyze, design and study results of each learner, and to present them in a form to suit the learner's characteristics in the $21^{\text {st }}$ century. The survey was designed in an appropriate language for the users in-mind and is certified by 5 experts from various fields, such as technology and educational communication, computational science, and computational process specialists. The researchers also conducted structured interviews with experts on current computational teaching and learning issues. They monitored trends in the virtual learning environment and learning issues related to computational teaching and used learning models in virtual environments to design questionnaires to suit the characteristics of high school students. The questionnaire matched the Conformity Index of the survey (IOC) and is suitable for high school students. Currently tablets are the device of choice for young children and this is because of their large screen sizes, high mobility, offline and online media streaming ability, decreasing cost, and increasing interactive capabilities [15]. Therefore, the online survey created using Microsoft Forms which can be used on computers, tablets and also on other mobile devices.

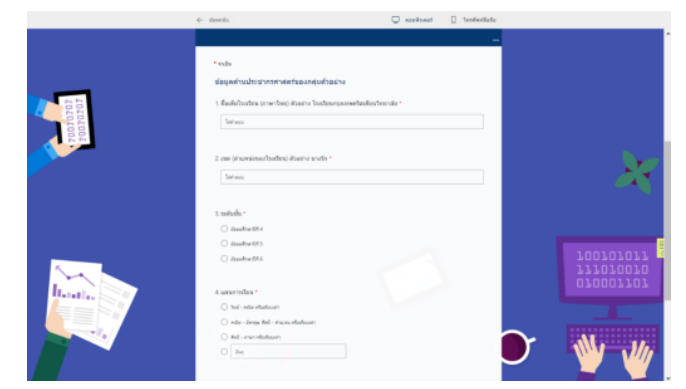

Fig. 2. Microsoft Forms when running on a computer 

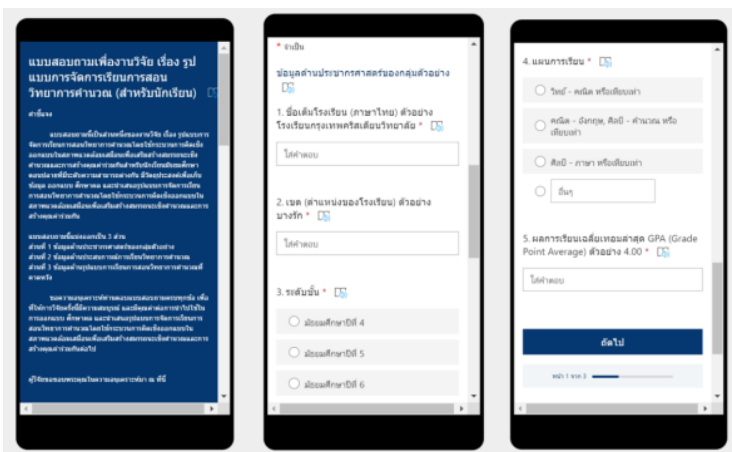

Fig. 3. Microsoft Forms when running on tablet and other mobile devices

The data was collected from a sample of 400 people who are real learners in computational science from government schools and private schools at the same ratio, as all high school students will study computational science courses. The researchers chose to perform a simple random sampling from the population of high school students across Bangkok. Using the Krejcie \& Morgan formula [16]; [17] To calculate the number of samples, the data collection took a total of 2 months, starting immediately after the students has completed the course of computational science in the first semester. The researchers distributed the questionnaire as an online link. For the convenience of students to answer questions.

The survey was divided into 3 parts: part 1, demographic data of the sample, part 2 Learning experience in computational science, and part 3 Learning expected in computational science teaching style. The questions in the research survey are as follows.

\section{Part 1 demographic data of the sample}

1. School Name e.g., Bangkok Christian College

2. District e.g., Bang Rak

3. Educational level

4. Study Plan e.g., Science-Mathematics

5. Grade Point Average (GPA) e.g., 4.00

\section{Part 2 Learning experience in computational science}

6. Current models for studying computational science

7. Learning experience in computational science (Likert scale)

i. Before studying, what level was the knowledge of computational science for high school students?

ii. To what extent are you satisfied with the current method of teaching computational science?

iii. How interesting is the current format for teaching computational science?

iv. Is the course content easy to understand?

v. Is it easy to learn and review the lesson content?

vi. Was there any collaboration between classes? 
vii. Do you know the measurement/ evaluation criteria in the computational science course?

viii. Is there a measurement/ assessment before, during and after study?

\section{Part 3 Learning expected in computational science teaching style}

8. Which of the following virtual learning environment do you know? (Can answer more than 1)

9. Learning expected in computational science teaching style (Likert scale)

i. What level of computational science can be used in daily life?

ii. Are you interested in self-study through the media with the teacher giving advice when encountering problems?

iii. What level of knowledge about online virtual learning environments do you have?

iv. What level are you interested in studying in an online virtual learning environment?

v. Are you interested in working with others?

vi. Step-by-step teaching and learning management; Is it important to the teaching of computational science?

vii. Are you interested in being free to learn and promote creativity in the work place? 10. Additional comments on the learning model of computational science.

Based on the above questions, the researchers were interested in knowing the teaching styles that students had studied and wanted to know the expectations of students in computational science. Further research into teaching styles is essential for learners in the $21^{\text {st }}$ century.

\subsection{The results of data collection}

The data was collected from a sample of 400 high school students across Bangkok, Thailand. The data was collected from both public and private schools. The data used in this study was analyzed in relation to the development of computational science teaching models only.

Table 1. The frequency of students' survey divided by Educational level

\begin{tabular}{|l|l|c|c|c|c|}
\hline \multicolumn{2}{|c|}{ Education level } & Frequency & Percent & Valid Percent & Cumulative Percent \\
\hline Valid & Grade 10 & 149 & 37.3 & 37.3 & 37.3 \\
\hline & Grade 11 & 145 & 36.3 & 36.3 & 73.5 \\
\hline & Grade 12 & 106 & 26.5 & 26.5 & 100.0 \\
\hline & Total & 400 & 100.0 & 100.0 & \\
\hline
\end{tabular}

Table 1 shows the total amount of respondents (400) divided by their grade; Grade 10, 149 people, representing $37.3 \%$, being Grade 11 , 145 people, representing $36.3 \%$, and being Grade 12 with 106 people, or $26.5 \%$

From the data analysis, it was found that there were two components suitable for use in the study; the design and development of teaching and learning models they consisted 
of the "Student Learning Experience" and "Student Learning Expected" in computational science. The researchers used one-way ANOVA statistical analysis to study the differences between the groups. (Table 2)

Table 2. Student Learning Experience and Student Learning Expected in computational science divided by Educational level, GPA and Current Learning Model.

\begin{tabular}{|c|c|c|c|c|c|}
\hline \multicolumn{6}{|c|}{$\begin{array}{l}\text { Student Learning Experiences divided by Educational Level, } \\
\text { GPA \& Learning Model }\end{array}$} \\
\hline & $n$ & Mean & $S D$ & $\boldsymbol{F}$ & $p$ \\
\hline \multicolumn{6}{|l|}{ Eduactional level } \\
\hline Grade 10 & 145 & 3.32 & .63 & 27.751 & .000 \\
\hline Grade 11 & 149 & 2.83 & .56 & & \\
\hline Grade 12 & 106 & 3.30 & .69 & & \\
\hline Total & 400 & 3.13 & .66 & & \\
\hline \multicolumn{6}{|l|}{ GPA } \\
\hline $3.00-4.00$ & 249 & 3.13 & .71 & .189 & .828 \\
\hline $2.00-2.99$ & 149 & 3.13 & .60 & & \\
\hline$<2.00$ & 7 & 3.29 & .37 & & \\
\hline Total & 400 & 3.13 & .66 & & \\
\hline \multicolumn{6}{|l|}{ Learning Model } \\
\hline In the classroom only & 178 & 3.09 & .66 & 4.634 & .202 \\
\hline Blends both online and in the classroom & 222 & 3017 & .67 & & \\
\hline Total & 400 & 3.13 & .66 & & \\
\hline \multicolumn{6}{|c|}{$\begin{array}{l}\text { Student Learning Experiences divided by Educational Level, } \\
\text { GPA \& Learning Model }\end{array}$} \\
\hline & $n$ & Mean & $S D$ & $\boldsymbol{F}$ & $p$ \\
\hline \multicolumn{6}{|l|}{ Eduactional level } \\
\hline Grade 10 & 149 & 3.64 & .79 & 13.7555 & .000 \\
\hline Grade 11 & 145 & 3.20 & .58 & & \\
\hline Grade 12 & 106 & 3.40 & .80 & & \\
\hline Total & 400 & 3.41 & .74 & & \\
\hline \multicolumn{6}{|l|}{ GPA } \\
\hline $3.00-4.00$ & 249 & 3.42 & .76 & .93 & .911 \\
\hline $2.00-2.99$ & 144 & 3.41 & .71 & & \\
\hline$<2.00$ & 7 & 3.53 & .73 & & \\
\hline Total & 400 & 3.41 & .74 & & \\
\hline \multicolumn{6}{|l|}{ Learning Model } \\
\hline In the classroom only & 178 & 3.35 & .75 & 2.560 & .110 \\
\hline Blends both online and in the classroom & 222 & 3.47 & .74 & & \\
\hline Total & 400 & 3.41 & .74 & & \\
\hline
\end{tabular}

$* \mathrm{p}<.05$

The analysis of the results showed the "Student Learning Experience" in computational science was divided by the educational levels and showed that there was a statistical difference of .05 level of significance. It was found that the students at each level have different teaching experiences. $($ mean $=3.13$, S.D. $=.66)$ 
Analyzing the data of the "Student Learning Experience" in computational science when dividing them by their GPA shows no difference in statistically. It was found that the students in all grade groups experience no difference in computational learning.

The analysis of the results shows that the "Student Learning Experience" in computational science when divided by "Current Learning Models" employed showed that there was no difference in statistically.

When reviewing the results of "Student Learning Expected" in computational science and dividing them by educational levels, it showed that there was a statistical difference of .05 level of significance. It was found that the students at each level have different expectations of the computational science learning. $($ mean $=3.41$, S.D. $=.74)$

Analyzing the data of "Student Learning Expected" in computational science and dividing them by their GPA shows that there was no difference in statistically. It was found that the students in every grade group had no difference in expectations of learning computational science.

Analysis of the results of "Student Learning Expected" in computational science was also divided by "Current Learning Models" and showed that there was no difference in statistically.
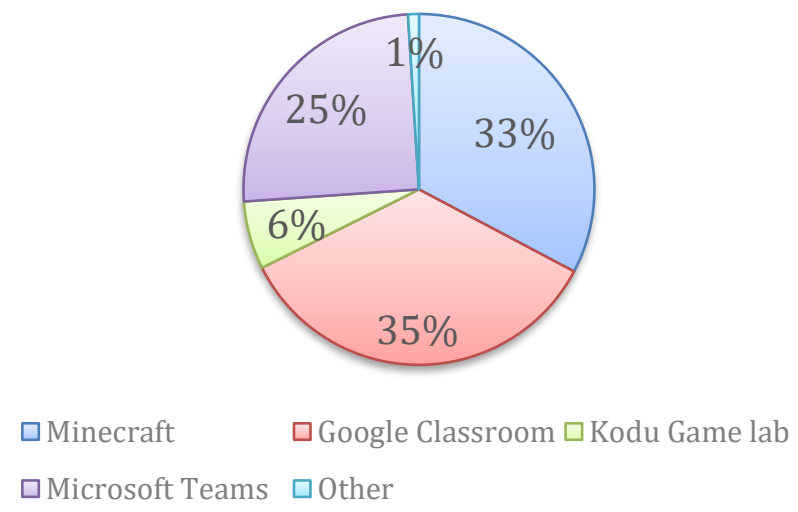

Fig. 4. Virtual Learning Environments that students recognized

Fig. 4 shows the "Virtual Learning Environments" that students are familiar with (Student could identify more than 1). Analysis show which platforms students are most familiar with; Minecraft 261 (33\%), Google Classroom 278 (35\%), Kodu Game lab 50 (6\%), Microsoft Teams 200 (25\%) and Other $8(1 \%)$

\subsection{Survey results}

Analysis of research survey data showed that the high school students at each level have different learning experiences and learning expectations in computational science. However, if classified by GPA and the current learning models, it found the students' knowledge of computational science is still low. They can improve their analytical 
thinking skills and problem solving in a step-by-step manner, whilst also utilizing systematic techniques, including computational thinking skills. The teaching and learning styles of today are both in the classroom and blended forms online. As a result of collecting the data we now know that the students are interested in the freedom to create their work without too much intervention. But at other times, they are interested in collaborating with others. Based on the above data, 33\% of participants knew of Minecraft virtual learning environments and that made Minecraft the most well-known for its ability to improve both computational competencies and other $21^{\text {st }}$ century skills.

Consistently, research has shown that learning games help students develop their critical thinking skills. And receiving a higher education therefore, higher education quality, results in higher educational achievement. And the personal is more desirable. Games have a huge impact on children, so learning games must combine features to support more efficient learning through technology [18]; [19]. And, according to [20] mentioned that teaching and learning in the virtual reality models that it is a technology that facilitates learning. Blended learning results in better results of students' critical thinking skills compared to normal classes. Therefore, the researcher wants to develop a model for teaching computational science in a virtual learning environment through Microsoft Teams, along with the use of games such as Minecraft Education Edition, a virtual environment focused on thinking and solving problems in a designed virtual environment. Allowing students to improve computational thinking into a competence that can be used in real life. Also, it enables the ability to develop other skills, which are essential skills in the $21^{\text {st }}$ century at the same time.

\section{$4 \quad$ Teaching Model in Virtual Learning Environment}

\subsection{Characteristics of teaching in a virtual learning environment}

From the literature it was found that the teaching model in a virtual learning environment encourages learners to understand to great extent, analyze the problem, evaluate options, and enable them to make effective decisions. Virtual classrooms have various other features, such as video clips, virtual reality, and social media [21]. It is an educational innovation that is taught through a network or online system which is a near-term or far-reaching connection via the Internet, where the teacher designs the learning system to have various media activities for students to learn and create interactions according to the situation, with telecommunications and networking allowing learners to learn anytime and anywhere [22]. 


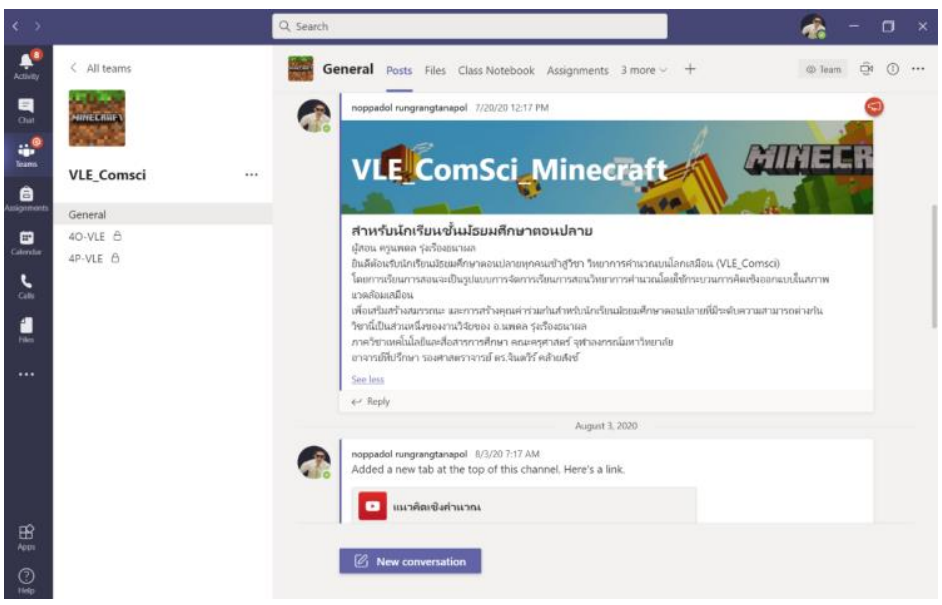

Fig. 5. Virtual Learning Environment with Microsoft Teams

\subsection{Core components of teaching in a virtual learning environment}

The components of teaching in a virtual learning environment consists of many elements based on the characteristic semantic analysis of the virtual learning environment, the components of teaching in a virtual learning environment can be summarized according to the following Table 3

Table 3. The Components of Teaching in a Virtual Learning Environment according based on the Characteristic semantic analysis of the Virtual Learning Environment

\begin{tabular}{|l|c|c|c|c|c|c|}
\hline $\begin{array}{c}\text { Issues of characteristics } \\
\text { of the virtual learning } \\
\text { environment by } \\
\text { definition }\end{array}$ & Gunawan (2018) & $\begin{array}{c}\text { Anusorn } \\
\text { and Paitoon } \\
\text { (2015) }\end{array}$ & $\begin{array}{c}\text { Rienties, } \\
\text { et la. } \\
\text { (2018) }\end{array}$ & $\begin{array}{c}\text { K.Kultaw } \\
\text { anich. } \\
\text { (2014) }\end{array}$ & $\begin{array}{c}\text { Alaberg, } \\
\text { T,et la. } \\
\text { (2017) }\end{array}$ & $\begin{array}{c}\text { Ziwapon, } \\
\text { et la. } \\
\text { (2018) }\end{array}$ \\
\hline $\begin{array}{l}\text { Simulate the situation or } \\
\text { context of the learner }\end{array}$ & $\checkmark$ & & & $\checkmark$ & $\checkmark$ \\
\hline Under structure or network & $\checkmark$ & & & $\checkmark$ & & $\checkmark$ \\
\hline $\begin{array}{l}\text { Design according to } \\
\text { learning objectives }\end{array}$ & $\checkmark$ & $\checkmark$ & & $\checkmark$ & $\checkmark$ & $\checkmark$ \\
\hline $\begin{array}{l}\text { Communication and } \\
\text { interaction** }\end{array}$ & $\checkmark$ & & & & $\checkmark$ & \\
\hline $\begin{array}{l}\text { Time coordinate format } \\
\text { and do not coordinate the } \\
\text { time dimension }\end{array}$ & & & & & & $\checkmark$ \\
\hline $\begin{array}{l}\text { Promote student's } \\
\text { aanalytical thinking and } \\
\text { problem solving*** }\end{array}$ & & $\checkmark$ & & $\checkmark$ & $\checkmark$ & $\checkmark$ \\
\hline Promote different learners* & & $\checkmark$ & $\checkmark$ & $\checkmark$ & $\checkmark$ & $\checkmark$ \\
\hline
\end{tabular}

*,**,*** Top 3 Characteristics of the virtual learning environmnet by definition

From the table 3, the researchers summarized the characteristics of the virtual classroom as a simulation of a situation, or the context of which learners are under the 
structure or network. According to learning objectives, which promotes communication and interaction between each other in time coordinate or do not coordinate the time dimension. The design of such a virtual classroom can promote critical thinking, systematic problem solving of the learner including being able to promote learning among learners with different characteristics.
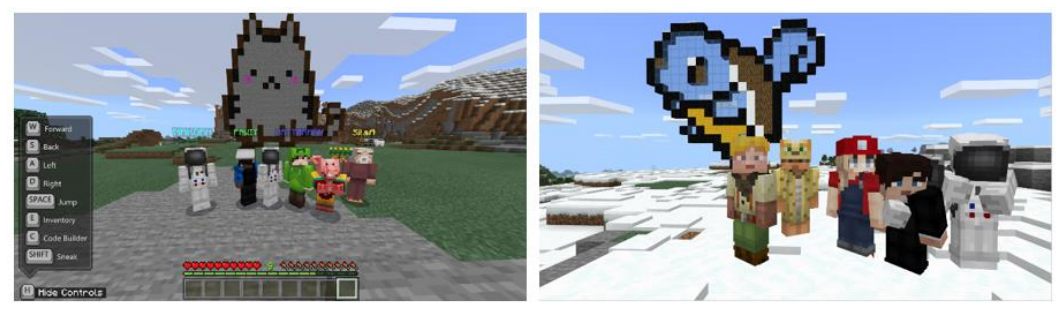

Fig. 6. Virtual Learning Environment with Minecraft Education Edition

\subsection{Problems and limitations of teaching in virtual learning environments}

From the data collection to conducting structured interviews with computational teaching professionals and teaching professionals in virtual environments, we found that teaching in a virtual learning environment can be seen in some ways today but not much due to the high-cost limitations of the devices and the classrooms themselves need to have relatively advanced technology to support the gameplay. To provide students with the learning experience that the instructor intended experts believe that teaching and learning in a virtual environment needs to continue to improve in the future.

\section{Discussion}

Recently, the rapid shift to online learning due to the spread of the Covid-19 virus in many countries made the need for mobile learning more imminent [7]. In an educational robotics environment, children can practice and develop model of cognitive processes that foster creative thinking, effective teamwork, social communication among others [24]; [25]. But the introduction of robots in education settings is a complicated task as it involves both the technical requirements and the school environment [26]; [25]. Planning, developing, designing teaching, and learning in virtual learning environments must be designed under an efficient process for to ensure learner's benefit. Researchers might choose to use a design thinking approach to develop systematic thinking processes along with encouraging teamwork between learners within a virtual learning environment with the intention to get students to understand the problem by brainstorming for a solution to a problem. It is also possible to test that approach and improve it before applying it to the most effective solution. The design depends on the context in which each institution must consider electronic devices and network resources. Most importantly, students need to develop their abilities in other fields. 


\section{Conclusion and Recommendations}

The study of the results of the questionnaire revealed the problems of the current Thai education system. This is because students have no experience in systematic thinking. Also, teaching and learning models are currently unable to promote computational competence and develop other 21 st century skills. So, planning, developing, and designing teaching model in a virtual learning environment is an important step in determining the direction and the approach of virtual classrooms. Gathering data from a group of real learners will give you a realistic insight of the needs of each class learner including experiences about the past learning styles and their expectations of students' learning in the future. Groups of learners is one of the factors that teachers need to focus on, because if the virtual environment is applied to a younger group or without experience in the use of a virtual environment, the learner will not be able to participate in the activities planned by the instructor. Therefore, teachers should study various factors to determine the guidelines for the use of clear teaching patterns e.g., time, conditions, measurement, and evaluation. This would provide students with an understanding and improved focus on studying via a virtual learning environment model stipulated by the instructor. As a result, learners could be well-prepared to deal with the challenges in the 21 st century.

\section{$7 \quad$ References}

[1] D. Kwak, "The 4th Industrial Revolution and Innovation in Education," presented at 8th TCU International e-Learning Conference 2017 (IEC2017), p. 4-11, 2017. Retrieved from http://www.thaicyberu.go.th/document/IEC2017/grandJuly20IEC2017DukHoonKwak IEC20170720.pptx

[2] D. V. Roekel, An Educator Guide to the "Four Cs", Preparing 21st century students for a global society, National Education Association, USA, 2012. [E-book].

[3] K. Kultawanich, "A learning system on Cloud-Based Virtual Classroom Based on a Connectivism Learning Concept to Enhance Information Literacy and Information Literacy selfefficacy of Undergraduate students," Chulalongkorn University Intellectual Repository (CUIR), 2014. https://doi.org/10.14457/CU.the.2014.725 https://doi.org/10.1016/j.sbspro. 2015.04.394

[4] D. Darmawan, "Development of ICMLS Version 2 (Integrated Communication and Mobile Laboratory Simulator) To Improve 4.0 Century Industry Skill in Vocational Schools," International Journal of Interactive Mobile Technologies (iJIM), vol. 14, no. 8, p. 97-113, 2020. https://doi.org/10.3991/ijim.v14i08.12625

[5] The Institute for the Promotion of Teaching Science and Technology: Science Technology Fundamentals Course Guide (Computational science) according to learning standards and indicators Science Education Group (Vol. Revised 2017) according to the basic education core curriculum, BE 2551, The Institute for the Promotion of Teaching Science and Technology, Ministry of Education, Bangkok, Thailand, 2018.https://doi.org/10.1007/978-0$\underline{\text { 585-34587-1_10 }}$

[6] Y. Poovarawan, "What is computational science?" school.dek-d.com, Jan. 24, 2018. https://school.dek-d.com/blog/kidcoding/computational-science/ 
[7] M. Drolia, E. Sifaki, S. Papadakis, M. Kalogiannakis, "An Overview of Mobile Learning for Refugee Students: Juxtaposing Refugee Needs with Mobile Applications' Characteristics" Challenges,11(2),31. 2020. https://doi.org/10.3390/challe11020031

[8] T. Aalberg, T. Mercun and M. Zumer, "Interactive Displays for the Next Generation of Entity - Centric Bibliographic Models," in Digital Libraries: Data, Information, and Knowledge for Digital Lives 19th International Conference on Asia-Pacific Libraries (ICADL), 2017 Bangkok, Thailand, 2017. https://doi.org/10.1007/978-3-319-70232-2_17

[9] S. Watcharapat, “Computing Science," scimath.org, Sep. 21, 2018. https://www.scimath.org/lesson-technology/item/8808-computing-science

[10] The Institute for the Promotion of Teaching Science and Technology, Ministry of Education: Course books Science and Technology Fundamentals (Computational Science), Chula Book Center. Bangkok, Chulalongkorn University, 2018.

[11] C. Keereerat, "Using the Problem-Solving and App Inventor to Develop Computational Thinking Skill for High School Students," Journal of Education Studies Chulalongkorn University, vol. 47, no. 2, p. 31-47, April-June 2019.

[12] T. Jagust, A. S. Krzic, G. Gladec, M. Grgic and I. Bojic, "What (de)motivates one to volunteer in K-12 STEM-C outreach activities?" IEEE Frontiers in Education Conference (FIE), 2017. https://doi.org/10.1109/fie.2017.8190724

[13] W. Gunawan, "E-Learning through social media in the virtual learning environment," 2nd Nommensen International Conference on Technology and Engineering, IOP Conf. Series: Materials Science and Engineering, 2018. https://doi.org/10.1088/1757-899x/420/1/012110

[14] A. Baiyere and H. Salmela, "Review: Disruptive Innovation \& Information Technology Charting a path," in 24th Australasian Conference on Information Systems 4-6 Dec, Melbourne, 2013.

[15] S. Papadakis \& M. Kalogiannakis "A research synthesis of the real value of self-proclaimed mobile educational applications for young children" Mobile learning applications in early childhood education, 1-19. 2020. https://doi.org/10.4018/978-1-7998-1486-3.ch001

[16] R. V. Krejcie and E. W. Morgan, "Determining Sample Size for Research Activities," Educational and Psychological Measurement, vol. 30, p.607-610, 1970. https://doi.org/10.1177/ $\underline{001316447003000308}$

[17] T. Akakul, Research methodology in behavioral sciences and social sciences. Bangkok, Faculty of education, UbonRatchathaniRajabhat University, 5th, 2000.

[18] B. Gros, "Digital games in education: The Design of games-based learning Environments," Journal of research on technology in education, vol. 40, no. 1, p. 23-38, 2007. https://doi.org/10.1080/15391523.2007.10782494

[19] N. Aljojo, "The Design and Implementation of a Mathematics Game-Base Learning Application for Primary Students," International Journal of Interactive Mobile Technologies (iJIM), vol. 12, no. 3, p. 142-152, 2018. https://doi.org/10.3991/ijim. v12i3.8739

[20] J. Ikhsan, K. Sugiyarto and T. Astuti, "Fostering Student's Critical Thinking through a Virtual Reality Laboratory," International Journal of Interactive Mobile Technologies (iJIM), vol. 14, no. 8, p. 183-195, 2020. https://doi.org/10.3991/ijim. v14i08.13069

[21] A. Hongkhunthod and P. Srifa, "Development of a Flipped-Classroom Learning System Model through Rhree Media Formats in Music Skills for Secondary School Studens," Kasetsart Educational Review, vol. 26, no. 2, p. 71-83, May-August 2015.

[22] Z. Charoenwong, T. Keskomon and A. Tamsat, "Virtual Classroom in Teaching and Learning for Nursing Students in Digital Age," Journal of the Royal Thai Army Nurses, vol. 19, no. 2, p. 120-128, May-Aug 2018. https://he01.tci-thaijo.org/index.php/JRTAN/article/ view/143970 
[23] B. Rienties, T. Lewis, R. McFarlane, Q. Nguyen and L. Toetenel, "Analytics in online and offline language learning environment: the role of learning design to understand student online engagement," Computer Assisted Language Learning, Nov. 2017. https://doi.org/10. 1080/09588221.2017.1401548

[24] L. G. C. Anzoátegui, M. I. A. R. Pereira, \& M. D. C. S. Jarrín. "Cubetto for preschoolers:Computer programming code to code" In 2017 International Symposium on Computers in Education (SIIE) (pp. 1-5), 9-11 November 2017, Lisbon, Portugal. IEEE. https://doi.org/10.1109/siie.2017.8259649

[25] S. Papadakis. "Robots and Robotics Kits for Early Childhood and First School Age." International Journal of Interactive Mobile Technologies (iJIM), 14 (18), 34-56, 2020. https://doi.org/10.3991/ijim.v14i18.16631

[26] F. Mondada, M. Bonani, F. Riedo, M. Briod, L. Pereyre, P. Rétornaz, \& S. Magnenat. "Bringing robotics to formal education: The thymio open-source hardware robot." IEEE Robotics \& Automation Magazine, 24(1), 77-85. https://doi.org/10.1109/mra.2016.2636372

\section{Authors}

Noppadol Rungrangtanapol is working as Computer teacher at Bangkok Christian College. Currently studying in a master's degree in Department of Educational Technology and Communications, Faculty of Education at Chulalongkorn University in Bangkok, Thailand. (noppadol.ru@bcc1852.com)

Jintavee Khlaisang Professor Dr. of Education at Department of Educational Technology and Communications, Educational Invention and innovation Research Unit, Faculty of Education, Chulalongkorn University Phayathai Rd., Wang Mai, Patumwan, Bangkok 10330 Thailand. *Corresponding author; (jintavee.m@chula.ac.th)

Article submitted 2021-02-05. Resubmitted 2021-04-28. Final acceptance 2021-04-28. Final version published as submitted by the authors. 